\title{
Transglutaminase 2 inhibits apoptosis induced by calcium- overload through down-regulation of Bax
}

\author{
Sung-Yup Cho ${ }^{1}$, Jin-Haeng Lee ${ }^{1}$, Han-Dong Bae, \\ Eui Man Jeong ${ }^{1}$, Gi-Yong Jang ${ }^{1}$, Chai-Wan Kim ${ }^{1}$, \\ Dong-Myung Shin ${ }^{1}$, Ju-Hong Jeon ${ }^{2}$ and \\ In-Gyu Kim ${ }^{1,3}$
}

\author{
${ }^{1}$ Department of Biochemistry and Molecular Biology/Aging and \\ Apoptosis Research Center (AARC) \\ ${ }^{2}$ Department of Physiology and Biophysics \\ Seoul National University College of Medicine \\ Seoul 110-799, Korea \\ ${ }^{3}$ Corresponding author: Tel, 82-2-740-8248; \\ Fax, 82-2-744-4534; E-mail, igkim@ plaza.snu.ac.kr \\ DOI 10.3858/emm.2010.42.9.063
}

Accepted 22 July 2010

Available Online 2 August 2010

Abbreviations: BP, 5-(biotinamido)pentylamine; HPRT1, hypoxanthine phosphoribosyltransferase 1; PARP, poly (ADP-ribose) polymerase; TG2, transglutaminase 2

\begin{abstract}
An abrupt increase of intracellular $\mathrm{Ca}^{2+}$ is observed in cells under hypoxic or oxidatively stressed conditions. The dysregulated increase of cytosolic $\mathrm{Ca}^{2+}$ triggers apoptotic cell death through mitochondrial swelling and activation of $\mathrm{Ca}^{2+}$-dependent enzymes. Transglutaminase 2 (TG2) is a $\mathrm{Ca}^{2+}$-dependent enzyme that catalyzes transamidation reaction producing cross-linked and polyaminated proteins. TG2 activity is known to be involved in the apoptotic process. However, the pro-apoptotic role of TG2 is still controversial. In this study, we investigate the role of TG2 in apoptosis induced by $\mathrm{Ca}^{2+}$-overload. Overexpression of TG2 inhibited the A23187-induced apoptosis through suppression of caspase- 3 and -9 activities, cytochrome $c$ release into cytosol, and mitochondria membrane depolarization. Conversely, down-regulation of TG2 caused the increases of cell death, caspase-3 activity and cytochrome $c$ in cytosol in response to $\mathrm{Ca}^{2+}$-overload. Western blot analysis of $\mathrm{Bcl}-2$ family proteins showed that TG2 reduced the expression level of Bax protein. Moreover, overexpression of Bax abrogated the anti-apoptotic effect of TG2, indicating that TG2-mediated suppression of Bax is responsible for inhibiting cell death under $\mathrm{Ca}^{2+}$-overloaded con-
\end{abstract}

ditions. Our findings revealed a novel anti-apoptotic pathway involving TG2, and suggested the induction of TG2 as a novel strategy for promoting cell survival in diseases such as ischemia and neurodegeneration.

Keywords: apoptosis; Bax; calcium; mitochondria; transglutaminase 2

\section{Introduction}

Precise regulation of free $\mathrm{Ca}^{2+}$ ion concentration in the cytosol is required for proper cellular signaling. A loss of $\mathrm{Ca}^{2+}$ homeostatic control, which is observed in heart and brain ischemia, over-stimulation of receptor by neurotransmitters and treatment of cytotoxic agents, is a major cause of cell death (Orrenius et al., 2003). The cytosolic overload of $\mathrm{Ca}^{2+}$ triggers mitochondrial permeability transition and cytochrome $c$ release to cytosol that results in activation of caspases, the apoptotic executioners (Orrenius et al., 2003). Increased $\mathrm{Ca}^{2+}$ ion also activates $\mathrm{Ca}^{2+}$-dependent enzymes including phospholipases, calpain and endonuclease which can affect the determination of cell fate (Dong et al., 2006).

Transglutaminase 2 (TG2) is a $\mathrm{Ca}^{2+}$-dependent enzyme that catalyzes acyl transfer reaction between the $\gamma$-carboxamide group of glutamine residues and the $\varepsilon$-amino group of lysine residues or polyamines (Lorand and Graham, 2003). In addition to $\mathrm{Ca}^{2+}$-dependent transamidation activity, TG2 also serves as a G-protein $\left(G_{h}\right)$ that binds and hydrolyzes GTP (Nakaoka et al., 1994), and as an integrin-associated co-receptor that mediates the interaction of integrins with fibronectin (Akimov et al., 2000).

TG2 has been reported to be induced in cells undergoing apoptosis in vivo (Fesus et al., 1987). TG2 thus has been suggested to inhibit the release of intracellular proteins and DNA from dying cells through catalyzing cross-linking of cellular proteins (Fesus et al., 1991). However, no difference in apoptosis between TG2 null thymocytes or mouse embryonic fibroblasts and wild type cells was observed when exposed to cytotoxic agents (De Laurenzi and Melino, 2001). Moreover, TG2 expression protected cells from stress conditions such as a treatment with $\mathrm{N}$-(4-hydroxyphenyl)retinamide (Antonyak et al., 2001), serum deprivation 

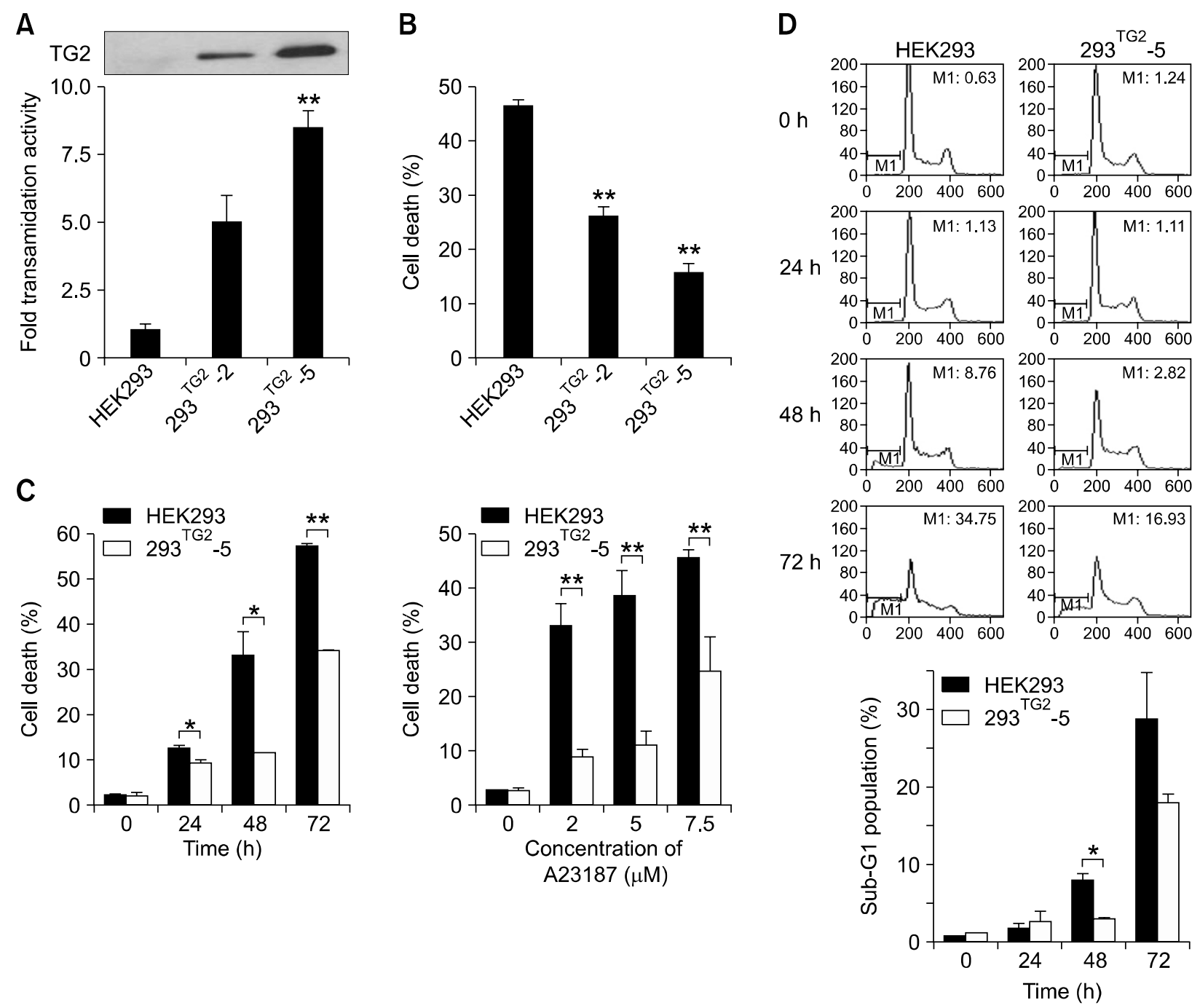

Figure 1. TG2 inhibits A23187-induced cell death. (A) TG activity in HEK293 cells overexpressing TG2 $\left(293^{T^{G} 2}-2\right.$ and $\left.293^{{ }^{T G 2}}-5\right)$. TG activity was expressed as relative value using HEK293 cells as a control. The level of TG2 expression was estimated by Western blot analysis (inset). (B) A23187-induced cell death in HEK293, $293^{\mathrm{TG2}}-2$ and $293^{\mathrm{TG2}}-5 \mathrm{cells}$. Cell death was quantitated by trypan blue staining after $48 \mathrm{~h}$ of treatment with $5 \mu \mathrm{M}$ A23187. (C) Time-dependent and dose-dependent cytotoxicity of A23187 in HEK293 and $293^{\text {TG2 }}-5$ cells. (D) Flow cytometry analysis of A23187-induced apoptosis in HEK293 and $293^{\text {TG2 }}-5$ cells determined by propidium iodide staining after treatment with $5 \mu \mathrm{M}$ A23187. M1 represents sub-G1 population. Data represent the mean $\pm \mathrm{SD}$ from three independent experiments. Asterisks indicate statistically significant differences $\left({ }^{*}, P<0.05 ;{ }^{* *}, P<0.01\right)$ compared with HEK293 cells.

(Antonyak et al., 2003) and doxorubicin (Antonyak et al., 2004). Therefore, TG2 is suggested to have different roles in apoptosis depending on cell type or stress (Fesus and Szondy, 2005).

Recently, we showed that oxidative stress triggers an increase of $\mathrm{Ca}^{2+}$ ion which activates TG2 in human lens epithelial cell line. Subsequently, TG2-mediated protein modification lowers the solubility of protein and therefore leads to the aggregation of substrate proteins (Shin et al., 2008). However, the role of TG2 in apoptosis induced by $\mathrm{Ca}^{2+}$-overload has not been elucidated. In this study, using TG2-overexpressed or down-re- gulated cells, we showed that TG2 protects cells from $\mathrm{Ca}^{2+}$ ionophore-induced cell death by inhibiting mitochondria-mediated apoptotic pathway through regulation of Bax, a regulator of mitochondrial permeability transition.

\section{Results}

\section{Inhibition of A23187-induced apoptosis by TG2}

To investigate the role of TG2 in apoptosis induced by $\mathrm{Ca}^{2+}$-overload, we examined the viability of established HEK293 cell lines which exhibit 
A

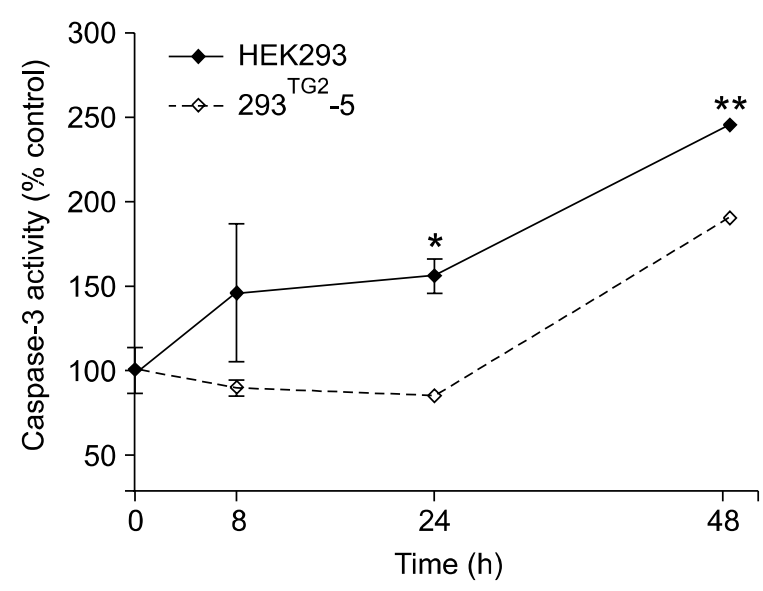

C

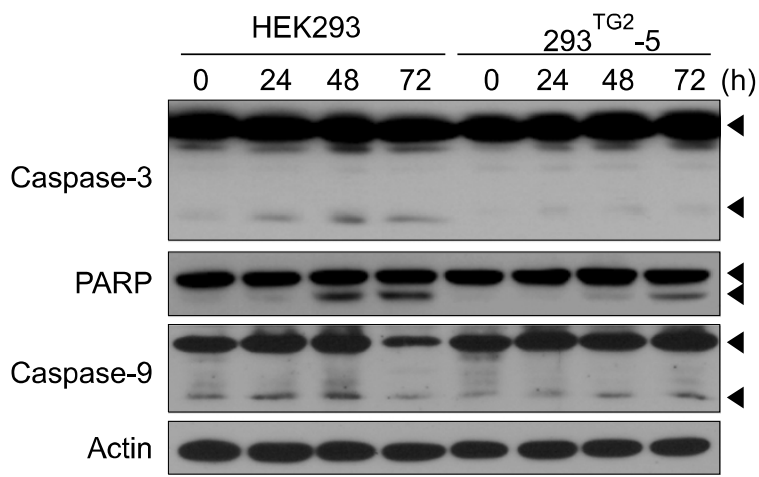

different levels of TG2 expression by treatment with $\mathrm{Ca}^{2+}$ ionophore. Western blot analysis and TG activity assay showed that the expression of TG2 was undetectable in native HEK293 cells, 5-fold higher in $293^{\text {TG2 }}-2$ cells, and 8.5 -fold higher in $293^{\text {TG2 }}-5$ cells (Figure 1A). HEK293 cells and its derivative cell lines overexpressing TG2 showed no difference in cell viability under normal culture conditions employed in this study (data not shown). In HEK293 cells, treatment with $5 \mu \mathrm{M}$ of A23187 resulted in almost $50 \%$ of cell death after $48 \mathrm{~h}$. By contrast, $293^{\text {TG2 }}-2$ and $293^{\text {TG2 }}-5$ cells were resistant to A23187-induced cell death (Figure 1B). There appears an inverse correlation between cell death rate and the level of TG2 expression $(26.1 \%$ cell death for $293^{\mathrm{T} 22}-2$ and $15.8 \%$ cell death for $293^{\text {TG2 }}-5$ ). The apparent protective effect of TG2 against the A23187-induced cell death sustained over a period of $72 \mathrm{~h}$ and for up to $7.5 \mu \mathrm{M}$ of A23187 (Figure 1C). To confirm these results, we examined apoptotic cell death by estimating the DNA content of A23187-treated cells after staining with propidium iodide. Flow cytometric analysis showed the increased percentage of sub-G1
B

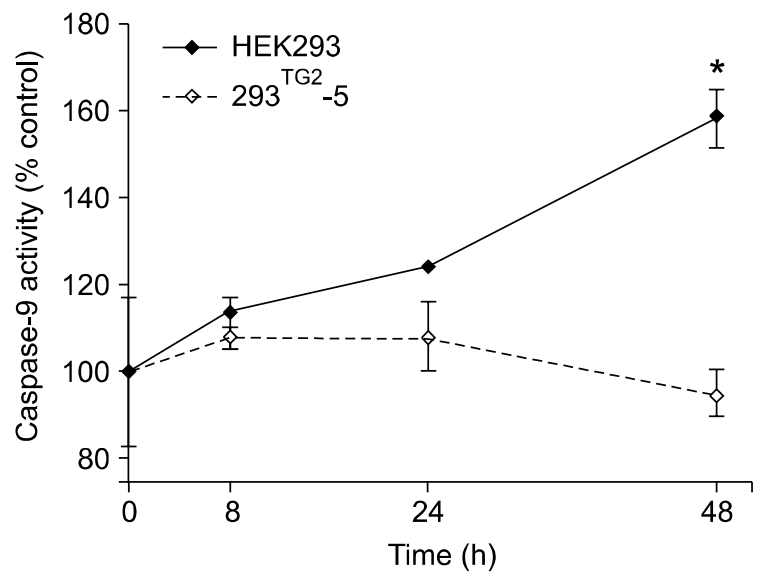

Figure 2. TG2 inhibits caspase- 3 and -9 activities of A23187-treated cells. (A) Caspase-3 activity of HEK293 and $293^{\text {TG2 }}-5$ cells after treatment with $5 \mu \mathrm{M}$ A23187. Cell lysate $(50 \mu \mathrm{g})$ was incubated with $2 \mathrm{mM}$ Ac-DEVD-pNA, and caspase-3 activity was determined by measuring absorbance at $405 \mathrm{~nm}$. Caspase-3 activity in the absence of A23187 was expressed as $100 \%$. (B) Caspase- 9 activity in HEK293 and $293^{\text {TQ2 }}-5$ cells after treatment with $5 \mu \mathrm{M}$ A23187. Caspase-9 activity was determined by using Ac-LEHD-pNA as a substrate. Data represent the mean $\pm S D$ based on three independent experiments. Asterisks indicate statistically significant differences $\left({ }^{*}, P<0.05\right.$; $\left.{ }^{* *}, P<0.01\right)$ compared with HEK293 cells. (C) Western blot analysis for caspase-3, poly (ADP-ribose) polymerase (PARP) and caspase-9.

phase cells in HEK293 cells compared with $293^{\mathrm{TC2}}-5$ cells under the same experimental conditions (Figure 1D).

\section{Inhibition of caspase activities by TG2}

To understand the mechanism responsible for anti-apoptotic role of TG2, we examined the effect of TG2 overexpression on caspase-3 activity. In HEK293 cells, exposure to $5 \mu \mathrm{M}$ A23187 induced the gradual increase of caspase- 3 activity for up to $48 \mathrm{~h}$. By contrast, increase of caspase- 3 activity in $293^{\mathrm{T} G 2}-5$ cells was significantly lower than that in HEK293 cells (Figure 2A). Western blot analysis also showed that activated form of caspase-3 appeared after $24 \mathrm{~h}$ in A23187-treated HEK293 cells, whereas treatment of $293^{\mathrm{TG} 2}-5$ cells with A23187 resulted in decreased cleavage of caspase-3 compared with control cells. These results were further verified by Western blot analysis of poly (ADP-ribose) polymerase (PARP) which showed decreased and delayed cleavage of PARP in $293^{\mathrm{TG} 2}-5$ cells compared with that of HEK293 cells (Figure $2 \mathrm{C}$ ). 
A

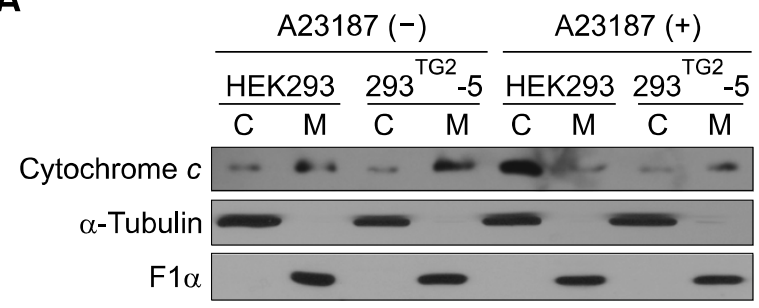

B

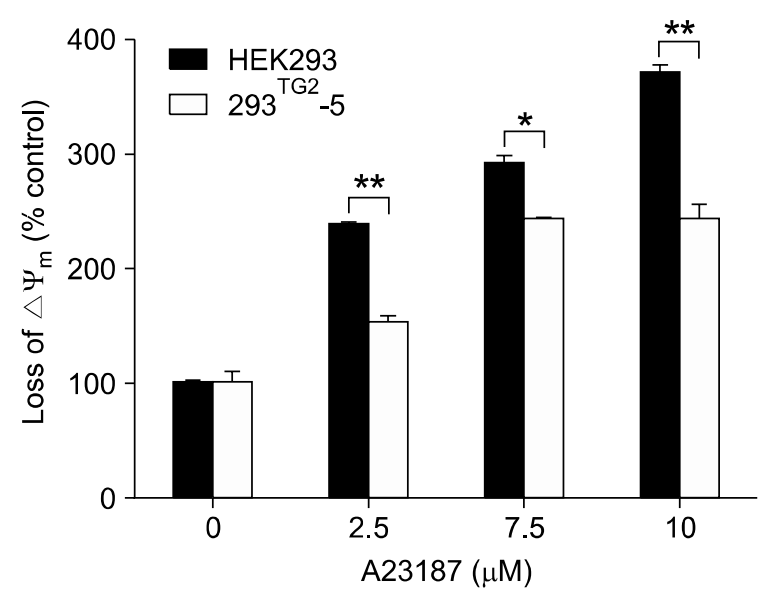

Figure 3. TG2 inhibits cytochrome $c$ release and mitochondria depolarization of A23187-treated cells. (A) Western blot analysis of cytochrome $C$ after treatment with $5 \mu \mathrm{M}$ A23187 for $48 \mathrm{~h}$ (C, cytosolic fraction; M, mitochondrial fraction). $\alpha$-tubulin and ATP synthase F1 $\alpha$ were used as cytosolic and mitochondrial markers, respectively. (B) Mitochondria membrane potential was analyzed by FACS using JC-1 after treatment with 5 $\mu \mathrm{M}$ A23187. A loss of mitochondria membrane potential was expressed as a relative percentage of cells showing reduced red fluorescence to that of the corresponding cells under the control condition. Asterisks indicate statistically significant differences $\left({ }^{*}, P<0.05\right.$; $\left.{ }^{* *}, P<0.01\right)$ compared with HEK293 cells.

Caspase- 9 is one of the upstream effecters of caspase-3 (Green, 1998). We then examined caspase- 9 activity of HEK293 and $293^{\text {TG2 }}-5$ cells. Treatment with A23187 increased caspase-9 activity in HEK293 cells, but had no effect on the activity of caspase-9 in $293^{\text {TG2 }}-5$ cells for up to 48 hr (Figure 2B). Western blot analysis showed that cleavage of caspase- 9 increased until $48 \mathrm{~h}$ and even full-length caspase- 9 decreased at $72 \mathrm{~h}$ in HEK293 cells, whereas cleavage of caspase-9 slightly increased only at $72 \mathrm{~h}$ in $293^{\text {TG2 }}-5$ cells. These results indicate that TG2 inhibits A23187-induced activation of caspase-3 and caspase-9.

\section{Inhibition of cytochrome $c$ release and mitochondria depolarization by TG2}

We next sought to understand how TG2 could inhibit activities of caspases. $\mathrm{Ca}^{2+}$ ionophores induce the release of cytochrome $c$ into cytoplasm from mitochondria (Orrenius et al., 2003). Cytochrome $c$ forms a complex with apoptosis protease-activating factor 1 (Apaf-1) and procaspase-9, which activates caspase-3 (Acehan et al., 2002). To test whether TG2 affects the $\mathrm{Ca}^{2+}$-induced release of cytochrome $c$, we compared the level of cytochrome $C$ in cytosolic and mitochondrial fraction after treatment with A23187. Western blot analysis revealed a similar amount of cytochrome $c$ in each fraction of HEK293 and $293^{\mathrm{T} G 2}-5$ cells under normal culture conditions. Treatment with A23187 increased the cytochrome $c$ in the cytosolic fraction of HEK293 cells with a concomitant decrease in mitochondrial fraction. By contrast, treatment with A23187 had minimal effect on the level of cytochrome $c$ in both cytosolic and mitochondrial fraction of $293^{\mathrm{TG} 2}-5$ cells (Figure $3 \mathrm{~A}$ ), indicating that TG2 inhibits the release of cytochrome $c$ from mitochondria by treatment of A23187.

Mitochondria membrane depolarization is an early event in the apoptotic signaling cascade of mitochondria that precedes cytochrome $c$ release (Honda et al., 2005). We therefore explored the possibility that TG2 might affect mitochondria membrane depolarization. Cells were incubated with JC-1 for 30 min and analyzed by flow cytometry. A23187 induced mitochondria membrane depolarization of HEK293 and $293^{\text {TG2 }}-5$ cells in a dose-dependent manner. However, in $293^{\mathrm{TG} 2}-5$ cells, the magnitude of mitochondria membrane depolarization was suppressed, and was not further increased above $7.5 \mu \mathrm{M}$ A23187 compared to HEK293 cells (Figure 3B). These results indicate that TG2 inhibits the release of cytochrome $c$ through suppression of mitochondrial membrane depolarization.

To further confirm the protective effect of TG2 in A23187-induced cell death, we established a HeLa cell line in which TG2 is down-regulated (Figure $4 \mathrm{~A})$. When treated the cells with $5 \mu \mathrm{M}$ of A23187 for $48 \mathrm{~h}, \mathrm{TG} 2$ knock-down cells showed the increase of cell death (Figure 4B), cleaved caspase-3 and cytochrome $C$ in cytosolic fraction (Figure 4C) compared with those in control cells, verifying the prosurvival role of TG2.

\section{Down-regulation of Bax protein by TG2}

It has been proposed that activated Bax or Bak is inserted into outer mitochondria membrane as a homo-oligomer to form channels through which cytochrome $c$ is released (Cory et al., 2003). We therefore examined the expression of $\mathrm{Bcl}-2$ family 
A

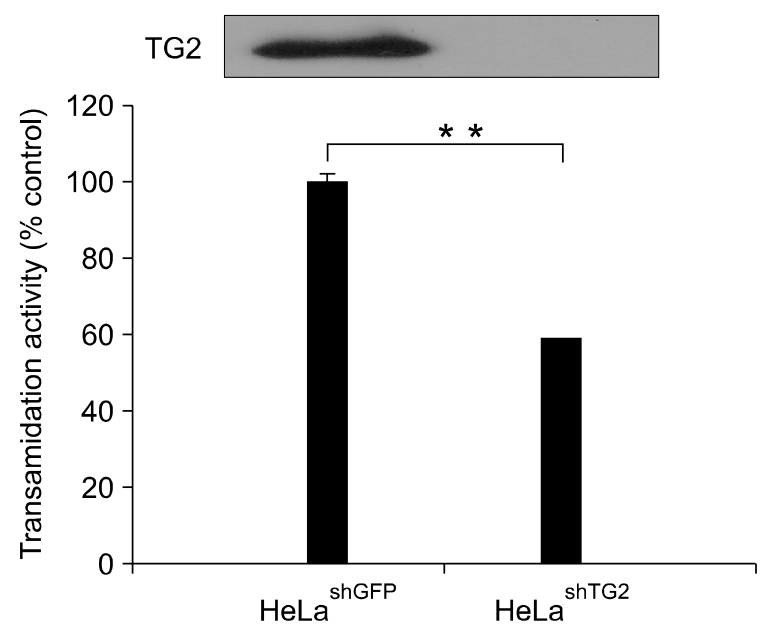

C

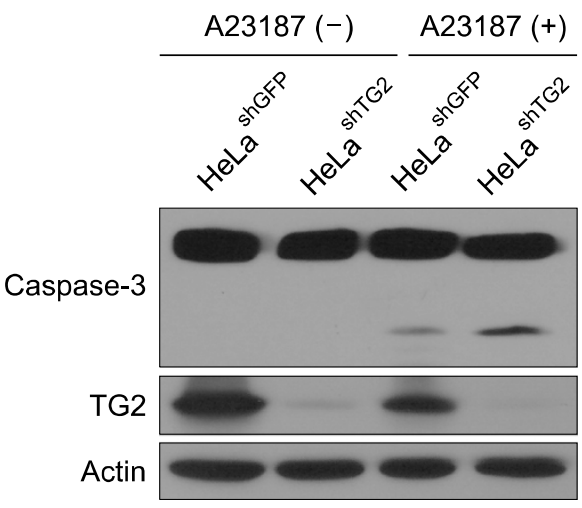

B
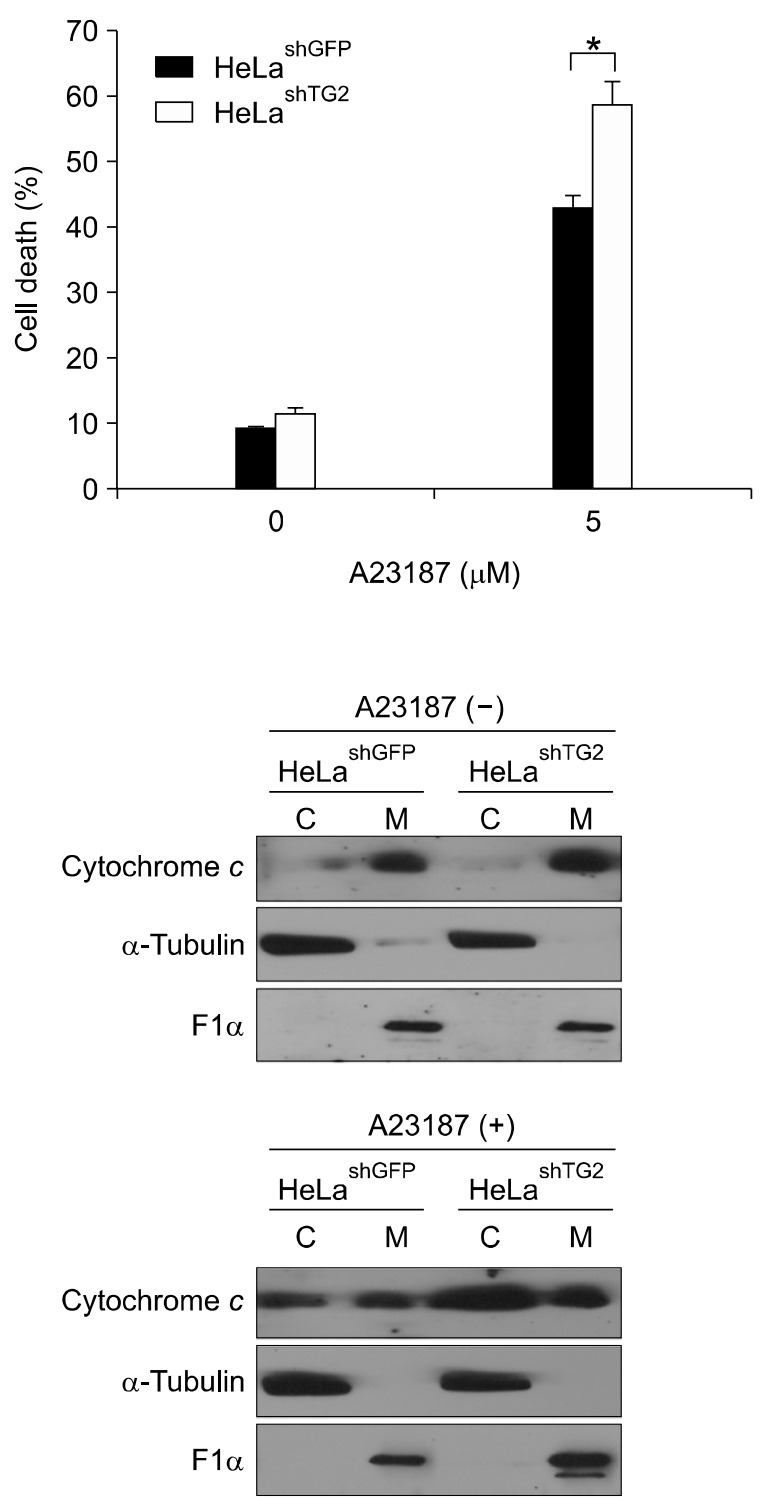

Figure 4. Effects of TG2 knock-down on A23187-induced cell death. (A) TG activity of TG2 knock-down (HeLa ${ }^{\text {shT2 }}$ ) and control (HeLa ${ }^{\text {shGFP }}$ ) HeLa cells. TG activity is expressed as relative value using HeLa ${ }^{\text {shGFP }}$ cells as a control. The level of TG2 expression is estimated by Western blot analysis. (B) A23187-induced cell death in HeLa ${ }^{\text {shGFP }}$ and HeLa ${ }^{\text {shT2 }}$ cells. Cell death was quantitated by trypan blue staining after $48 \mathrm{~h}$ of treatment with $5 \mu \mathrm{M}$ A23187. (C) Western blot analysis of caspase- 3 and cytochrome $c$ after $48 \mathrm{~h}$ of treatment with $5 \mu \mathrm{M} \mathrm{A23187} \mathrm{(C,} \mathrm{cytosolic} \mathrm{fraction;} \mathrm{M,} \mathrm{mitochondrial} \mathrm{fraction).}$ $\alpha$-tubulin and ATP synthase F1 $\alpha$ were used as cytosolic and mitochondrial markers, respectively. Asterisks indicate statistically significant differences $\left({ }^{*}\right.$, $\left.P<0.05 ;{ }^{* *}, P<0.01\right)$ compared with HeLa ${ }^{\text {shGFP }}$ cells.

proteins after A23187 treatment. Western blot analysis showed that the levels of $\mathrm{Bcl}-2, \mathrm{Bcl}-\mathrm{X}_{\mathrm{L}}$ and phospho-Bad protein were similar in both cell lines. Interestingly, the level of Bax in $293^{\mathrm{TG} 2-5}$ cells was lower than that in HEK293 cells, and was further decreased after A23187 treatment (Figures $5 A$ and $5 B$ ). Using $293^{\mathrm{TG2}}-2$ and $293^{\mathrm{TG2}}-5$ cell lines, we found that the level of Bax was inversely correlated with that of TG2. Consistently, the level of Bax in TG2 knock-down HeLa cells was higher than that in control cells (Figure $5 \mathrm{C}$ ). Moreover, transient overexpression of TG2 in HEK293 cells resulted in decrease of Bax level and transfection of shRNA expressing vector for TG2 in $293^{\mathrm{TG2}}-5$ cells increased the level of Bax protein (Figure 5D).

TG2 is reported to be required for translocation of Bax to mitochondria (Malorni et al., 2009). We thus examined the protein level of Bax in cytosolic 
A

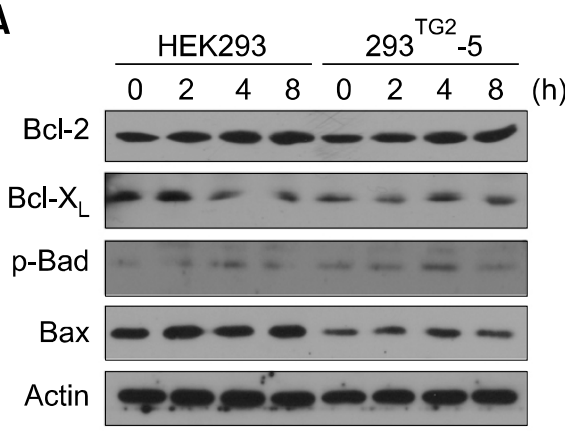

C

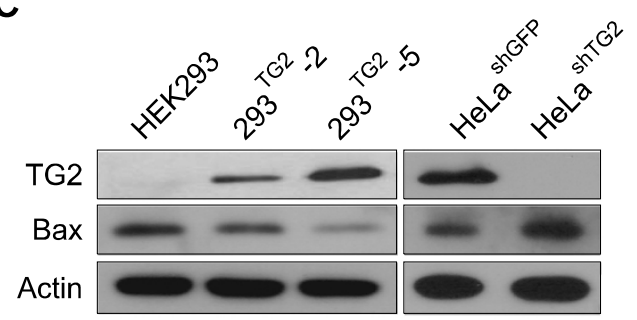

B

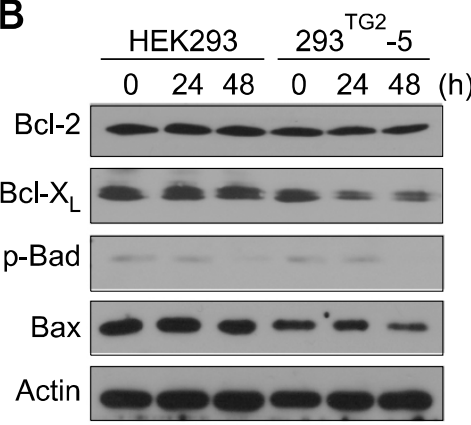

D

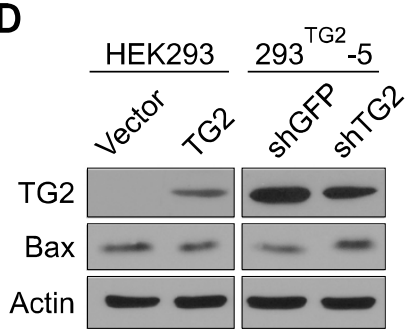

$\mathbf{F}$
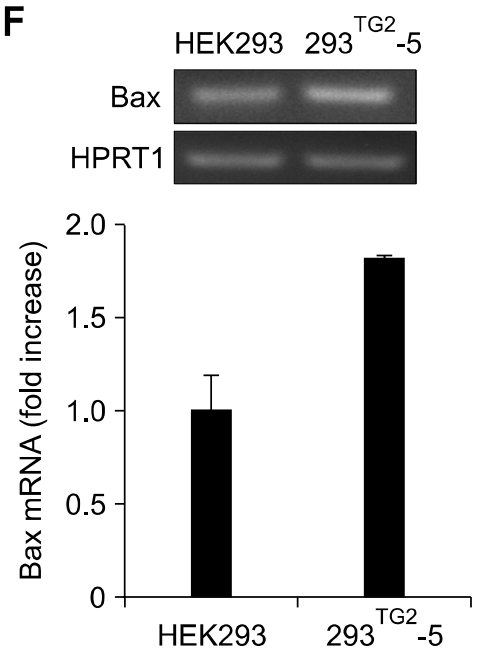

G
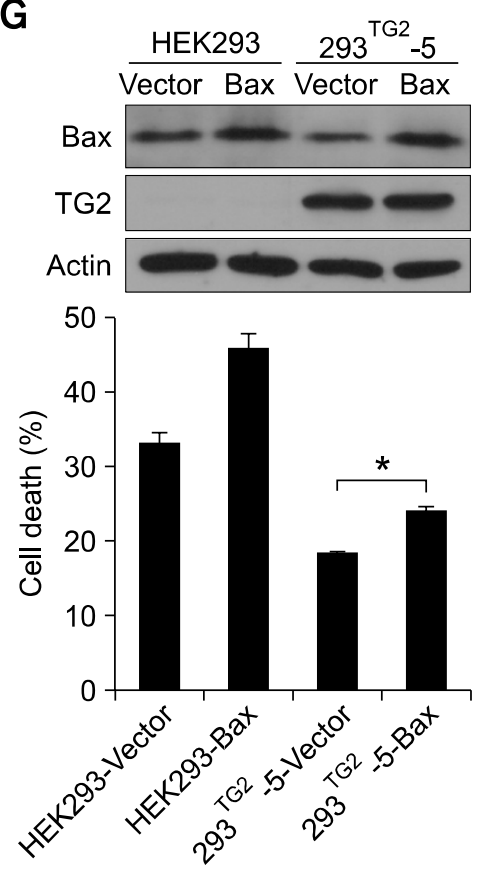

Figure 5. TG2 suppresses the protein level of Bax in the A23187-treated cells. (A, B) Western blot analysis of Bcl-2 family proteins after treatment with 5 $\mu \mathrm{M}$ A23187 in HEK293 and $293^{\mathrm{TS} 2}-5$ cells at early (A) and late (B) time points. (C) Protein level of Bax in TG2-overexpressed HEK293 cells (293 ${ }^{\mathrm{TG2}}-2$ and $293^{\text {TG2 }}$-5) or in TG2-downregulated HeLa cells (HeLa ${ }^{\text {shTG2 }}$ ). (D) Protein level of Bax after transient transfection of TG2-expressing vector in HEK293 cells or TG2-knockdown vector (expressing shRNA for TG2; shTG2) in $293^{\mathrm{TG} 2}-5$ cells. (E) Protein level of Bax in cytosolic and mitochondrial fraction from HEK293 and 293TG2-5 cells after treatment with $5 \mu \mathrm{M}$ A23187 for $48 \mathrm{~h}$ (C, cytosolic fraction; M, mitochondrial fraction). The numbers below the first panel indicate relative densitomeric intensities of Bax proteins. Cytosolic and mitochondrial fractions were compared with cytosolic and mitochondrial fractions of untreated HEK293 cells, respectively. $\alpha$-tubulin and ATP synthase F1 $\alpha$ were used as cytosolic and mitochondrial markers, respectively. (F) Quantification of Bax mRNA in HEK293 and $293^{\mathrm{TG} 2}-5$ cells using conventional (upper panel) and real-time PCR method (lower panel). Hypoxanthine phosphoribosyltransferase 1 (HPRT1) was used as internal control. (G) Effect of Bax expression on A23187-induced cell death in HEK293 and $293^{\text {TG2 }}-5$ cells. Cell death was quantitated by trypan blue staining after $48 \mathrm{~h}$ of treatment with $5 \mu \mathrm{M} \mathrm{A23187.} \mathrm{Asterisks} \mathrm{indicate} \mathrm{statistically} \mathrm{significant} \mathrm{differences}{ }^{*}$, $P<0.05)$ compared with vector-transfected $293^{T G 2}-5$ cells.

and mitochondrial fraction (Figure $5 \mathrm{E}$ ). In normal culture conditions, the level of Bax in mitochondrial fraction was lower in $293^{\mathrm{T} 2}-5$ cells than in control cells. After treatment of A23187, the level of Bax in mitochondrial fraction of $293^{\mathrm{TG} 2}-5$ cells further decreased, suggesting that resistance to A23187-induced apoptosis in $293^{\mathrm{TG} 2}-5$ cells is probably due to the low level of mitochondrial Bax. To test 

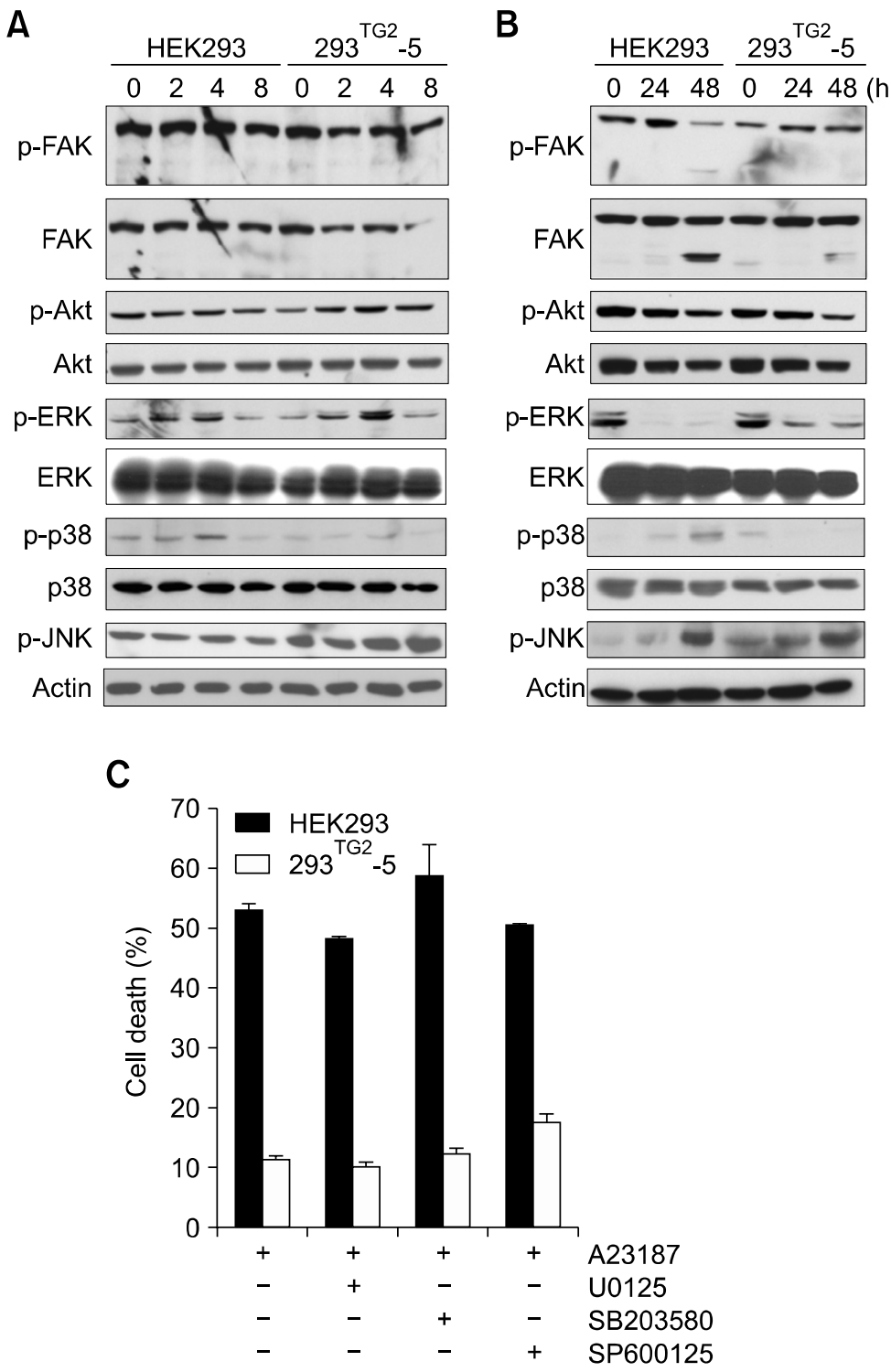

Figure 6. Effect of MAPK expression on A23187-induced cell death. (A, B) Western blot analysis of FAK, Akt, ERK, p38, and JNK after treatment with $5 \mu \mathrm{M}$ A23187 in HEK 293 and $293^{\mathrm{TG}}-5$ cells at early (A) and late (B) time points. Phosphorylated proteins are indicated as $\mathrm{p}$-. Actin was employed as a loading control. (C) Effect of MAPK inhibitors on A23187-induced cell death. U0125 $(10 \mu \mathrm{m}), \operatorname{SB} 203580(5 \mu \mathrm{m})$ and SP600125 $(10 \mu \mathrm{m})$ were used for inhibition of ERK, p38 and JNK, respectively. Cell death was evaluated by trypan blue staining after $48 \mathrm{~h}$ of treatment with $5 \mu \mathrm{M} \mathrm{A} 23187$.

whether TG2 suppresses Bax expression at the transcriptional level, we quantitated the mRNA of Bax in both cell lines. On the contrary to protein level, the mRNA level of Bax was slightly increased in $293^{\mathrm{TC2}}-5$ cells (Figure $5 \mathrm{~F}$ ), suggesting that low level of Bax protein is attributed to post-transcriptional regulation. Moreover, the anti-apoptotic effect of TG2 was abrogated about $40 \%$ by overexpression of Bax in $293^{\mathrm{T} 22}-5$ cells (Figure $5 \mathrm{G}$ ). These results indicate that TG2 inhibits cell death induced by $\mathrm{Ca}^{2+}$-overload through down-regulation of Bax protein, especially in mitochondria.

\section{Effect of TG2 on MAPK activity}

TG2 has been known to interact with $\alpha 5 \beta 1$ integrin that transmits intracellular signaling via FAK (Akimov et al., 2000; Parsons, 2003). MAPKs, downstream kinases of FAK, are involved in the regulation of cellular responses including apoptosis. The activation of JNK and p38 is associated with promotion of apoptosis, while ERK activity inhibits apoptosis (Reddy et al., 2003). To test whether TG2 inhibits $\mathrm{Ca}^{2+}$-induced apoptosis via interaction with integrin, we first examined the activity of FAK and its downstream kinases in HEK293 and $293^{\text {TG2 }}-5$ cells in response to A23187 treatment. The levels of $p$-FAK and p-Akt appeared similar in both cell lines. Under the same conditions, the level of $p$-ERK $1 / 2$ was decreased after $24 \mathrm{~h}$ in both cell lines. The level of p-p38 was increased only in HEK293 cells, while that of p-JNK were 
increased in $293^{\mathrm{TG} 2}-5$ cells (Figures $6 \mathrm{~A}$ and $6 \mathrm{~B}$ ). We then examined the effect of MAPK inhibitors on A23187-induced cell death. Treatment with MAPK inhibitors had no effect on cell survival of HEK293 as well as $293^{\mathrm{TG2}}-5$ cells (Figure $6 \mathrm{C}$ ), indicating that MAPK activities are not associated with anti-apoptotic role of TG2 in response to $\mathrm{Ca}^{2+}$-overload.

\section{Discussion}

$\mathrm{Ca}^{2+}$ has been suggested as an important regulator in the determination of cell fate. An abrupt increase of intracellular $\mathrm{Ca}^{2+}$ is found in various conditions including ischemia-reperfusion injury, receptor over-stimulation and oxidative stress (Orrenius et al., 2003). Increased cytosolic $\mathrm{Ca}^{2+}$ induces mitochondrial $\mathrm{Ca}^{2+}$ uptake, which causes mitochondrial swelling, mitochondrial membrane rupture, and cytochrome $c$ release to cytosol. In the present study, we have demonstrated a mechanism for the anti-apoptotic role of TG2 under $\mathrm{Ca}^{2+}$-overloaded conditions. An increase of intracellular $\mathrm{Ca}^{2+}$ activated TG2 which in turn induced the down-regulation of Bax protein. TG2-mediated regulation of Bax stabilized mitochondria membrane, suppressed the cytochrome $c$ release, and subsequently inhibited the cell death.

The TG2-mediated modifications of substrate proteins have been implicated in many cellular processes including differentiation, cell adhesion, extracellular matrix formation and apoptosis (Lorand and Graham, 2003). However, the role of TG2 in apoptosis is still controversial. The suppression of TG2 in U937 cells resulted in decreased cell death (Oliverio et al., 1999). Overexpression of TG2 sensitized neuronal cells to apoptosis (Piacentini et al., 2002) and activated caspase-3 in HEK293 cells (Milakovic et al., 2004). On the other hand, TG2 inhibits apoptosis induced by doxorubicin (Antonyak et al., 2004), TNF- $\alpha$ (Kweon et al., 2004), and dexamethasone (Nanda et al., 2001). Our findings, combined with the previous results, indicate that the role of TG2 in apoptosis depends on cell type as well as apoptogenic stress (Boehm et al., 2002; Tucholski and Johnson, 2002). Previous study showed conflicting results with our study in the role of TG2 in apoptosis induced by increase of intracellular $\mathrm{Ca}^{2+}$, in which, when transiently overexpressed, TG2 aggravated the thapsigargin-induced activation of caspase 3 (Milakovic et al., 2004). However, although both A23187 and thapsigargin increase cytosolic $\mathrm{Ca}^{2+}$, activation of caspase-3 was observed only in thapsigargin-treated SK-N-SH cells (Humar et al.,
2009). In contrast to $A 23187$, thapsigargin inhibits endoplasmic reticulum $\mathrm{Ca}^{2+}$-ATPase and thus induces the depletion of intracellular $\mathrm{Ca}^{2+}$ stores by long-term treatment, suggesting that machanism and kinetics of $\mathrm{Ca}^{2+}$ increase may affect the TG2-mediated regulation of Bax. In addition, subcellular localization of TG2 is also known to be associated with cellular response to apoptotic stimuli (Gundemir and Johnson, 2009). However, the effects of nuclear localization of TG2 varied depending on stimuli and conformational status of TG2. Therefore, further investigations are necessary to elucidate the mechanisms that determine the role of TG2 in the apoptotic process under various conditions.

$\mathrm{Bcl}-2$ protein family plays a pivotal role in apoptosis induced by $\mathrm{Ca}^{2+}$-overload. $\mathrm{Ca}^{2+}$ activates calcineurin which induces dephosphorylation of Bad (Orrenius et al., 2003). The dephosphorylated Bad activates Bax, which trigger the release of cytochrome $c$ via the formation of mitochondria permeability transition pore. Indeed, the cells that were deficient of both Bax and Bak manifested a resistance to apoptosis induced by thapsigargin treatment (Wei et al., 2001), indicating the critical role of $\mathrm{Bax}$ in the apoptosis induced by $\mathrm{Ca}^{2+}$-overload. In this study, we showed the inverse correlation between TG2 and Bax expression. Consistent with our results, Bax expression was increased by antisense oligonucleotide for TG2 (Lee et al., 2005). Although TG2 has been reported to modulate several transcription factors such as p53 (Tucholski, 2010), NF-kB (Jang et al., 2010) and SP1 (Tatsukawa et al., 2009), at present, the molecular mechanism by which TG2 regulates the expression level of Bax is unknown. One intriguing point is that the difference of protein level between control and $293^{\text {TG2 }}-5$ cells was larger than that of mRNA level (Figures $5 \mathrm{C}$ and $5 \mathrm{~F}$ ), suggesting that TG2 regulates the expression of Bax at post-transcriptional level. Bax may be a substrate for TG2 and, therefore, TG2 forms a cross-linked multimer of $\mathrm{Bax}$ or mediates modifications of Bax, which promotes the formation of insoluble aggregates (Rodolfo et al., 2004). However, we could not detect any multimers of Bax in our experimental conditions. Recently, TG2 was suggested to decrease Bax stability through cross-linking and depletion of nucleophosmin, a Bax chaperone (Park et al., 2008).

Our results have demonstrated that TG2 protects cells from $\mathrm{Ca}^{2+}$ overload by down-regulation of Bax. However, overexpression of Bax did not completely abrogate the protective effect of TG2 (Figure 5G). Considering the protein levels of Bax, this result was partly due to low efficiency of 
transient transfection in overexpressing Bax. Another possibility is the modulating effect of TG2 on other survival factors than Bax, such as up-regulation of cellular inhibitor of apoptosis 2 (cIAP2) and inhibition of caspase-3 under stressed conditions (Jang et al., 2010).

It has been reported that over-expression of TG2 in SK-N-BE cells resulted in hyperpolarization of mitochondrial membrane and MEFs prepared from TG2 knock-out mice exhibited hypopolarized mitochondrial membrane (Piacentini et al., 2002; Malorni et al., 2009). By contrast, our TG2-overexpressed HEK293 cell lines showed similar mitochondrial membrane potential to control cell line in normal culture conditions. Role of TG2 in apoptotic process was reported to be different in a cell-type dependent manner. Therefore, it is likely that the effect of TG2 on mitochondrial membrane potential also seems to be cell-type dependent, which needs further investigations.

TG2 has been proposed to have roles in the function of mitochondria. Since TG2 activity is detectable in mitochondria, many mitochondrial proteins including Bax, heat shock protein 60 , prohibitin and ATP synthase $\beta$-chain are expected to be modified by TG2 (Rodolfo et al., 2004; Battaglia et al., 2007). TG2 deficient mice exhibited reduced activity of mitochondrial complex I, as well as reduced ATP level in heart and skeletal muscle after a prolonged physical exercise (Mastroberardino et al., 2006; Battaglia et al., 2007). Consequently, the TG2 deficient mice were more vulnerable to a cardiac ischemia/reperfusion injury due to the defects in mitochondrial ATP production (Szondy et al., 2006). Taken together, these observations support our findings that TG2 inhibits mitochondria-mediated apoptosis triggered by an overload of intracellular $\mathrm{Ca}^{2+}$.

Previous reports have suggested the involvement of TG2 in signal transduction of MAPKs pathways. ERK, p38 and JNK were activated by TG2 via the polyamination of RhoA in neuronal differentiation of SH-SY5Y cells (Singh et al., 2003). In calphostin C-induced apoptosis, TG2 was known to activate JNK in response to calphostin C (Robitaille et al., 2008). Our results showed that TG2 activates ERK and JNK, while TG2 inhibit p38 in A23187-treated cells. Although effects of TG2 on MAPKs were not associated with cell death, role of TG2 in the regulation of MAPKs needs further investigation.

In summary, we showed that TG2 inhibits A23187-induced apoptosis via the down-regulation of Bax expression. Our findings suggest that induction of TG2 expression could be a novel strategy to prevent apoptosis in ischemic diseases of brain and heart.

\section{Methods}

\section{Establishment of cell lines that overexpress or down-regulate TG2}

HEK293 cells that overexpress TG2 $\left(293^{\mathrm{TG} 2}-2\right.$ and $293^{\text {TG2 }}-5$ ) were established as described previously (Jeon et al., 2003). In brief, HEK293 cells were transfected in $60-\mathrm{mm}$ dish with full length cDNA $(2 \mu \mathrm{g})$ of human TG2 in pcDNA3 (Invitrogen), or empty vectors, using Lipofectamine (Invitrogen). Forty-eight hours after transfection, the cells were treated with $400 \mu \mathrm{g} / \mathrm{ml}$ geneticin (Invitrogen) for 3 weeks. Geneticin-resistant clones were isolated and maintained for further analysis. HeLa cell lines that down-regulate TG2 (HeLa ${ }^{\text {shTa2 }}$ ) were established by transfection with pSUPER plasmid containing shRNA for TG2 or GFP. The target sequences for TG2 and GFP were 5'-GGGCGAACCACCTGAACAA-3' and 5'-GCAAGCTGACCCTGAAGTTC-3', respectively (Brummelkamp et al., 2002; Hwa Kim et al., 2005). The cells were selected with $800 \mu \mathrm{g} / \mathrm{ml}$ of geneticin for 2 weeks. The expression of TG2 was confirmed by Western blot analysis.

\section{TG activity assay}

TG activity was measured by microtiter plate method using $\mathrm{N}, \mathrm{N}$ '-dimethylcasein and 5-(biotinamido)pentylamine (BP) as substrates (Slaughter et al., 1992). Briefly, $3 \mu \mathrm{g}$ of $\mathrm{N}, \mathrm{N}$ '-dimethylcasein in $100 \mu \mathrm{l}$ coating buffer $(50 \mathrm{mM}$ Tris-Cl, pH 7.5, $150 \mathrm{mM} \mathrm{NaCl}, 5$ mM EGTA, 5 mM EDTA) was added to each well of a 96-well microtiter plate. Subsequently, each well was overcoated with $200 \mu$ of $3 \%$ bovine serum albumin (BSA) in phosphate buffered saline with $0.1 \%$ tween-20 (PBS-T) for $2 \mathrm{~h}$ at $37^{\circ} \mathrm{C}$. After washing with PBS-T, cell lysate (50 $\mu \mathrm{g}$ of protein) and $50 \mu \mathrm{M}$ BP in $50 \mu \mathrm{l}$ TG reaction buffer $(50 \mathrm{mM}$ Tris- $\mathrm{Cl}, \mathrm{pH} 7.5,10 \mathrm{mM}$ $\mathrm{CaCl}_{2}, 0.5 \%$ Triton X-100, $1 \mathrm{mM}$ DTT) were added to the wells and incubated for $1 \mathrm{~h}$ at $37^{\circ} \mathrm{C}$. To each well, $50 \mu \mathrm{l}$ of horseradish peroxidase conjugated streptavidin (Jackson Laboratory) in PBS-T with 3\% BSA was added and incubated for 1 hour at RT. After adding $50 \mu$ of substrate solution $(0.4 \mathrm{mg} / \mathrm{ml}$ o-phenylenediamine dihydrochloride in $50 \mathrm{mM}$ sodium citrate phosphate, $\mathrm{pH} 5.0$ ), the plate was incubated for $15 \mathrm{~min}$ at RT. The reaction was stopped by adding $1 \mathrm{M} \mathrm{H}_{2} \mathrm{SO}_{4}$, and the incorporation of $\mathrm{BP}$ was quantitated by measuring the absorbance at $490 \mathrm{~nm}$ using microplate spectrophotometer (Molecular Devices).

\section{Apoptosis assay}

Apoptotic cell death was determined by trypan blue exclusion assay or FACS analysis using propidium iodide. After A23187 treatment, cells were trypsinized and then centrifuged at $1,000 \times g$ for $5 \mathrm{~min}$. Both dead cells floating in the medium and the cells attached to the plate were recovered and resuspended in $500 \mu$ medium. Trypan blue exclusion assay was performed using a kit (Invitrogen). For cytometric analysis, cells $\left(1 \times 10^{6}\right)$ were fixed in $70 \%$ ethanol and resuspended in $200 \mu \mathrm{l}$ of PBS containing 50 $\mu \mathrm{g} / \mathrm{ml}$ propidium iodide and $100 \mu \mathrm{g} / \mathrm{ml}$ RNase A. After incubating for $30 \mathrm{~min}$ at $\mathrm{RT}$, the cells were analyzed by 
flow cytometry (Becton Dickinson) using the ModFit LT V3.0 software (Verity Software House).

\section{Caspase activity assay}

Caspase activities were measured using chromogenic substrates, Ac-DEVD-pNA and Ac-LEHD-pNA (A.G. Scientific Inc.) for caspase-3 and caspase-9, respectively, as previously described with minor modifications (Gu et al., 2003). The cells were lysed in buffer (50 mM HEPES, pH 7.4, $0.1 \%$ CHAPS, $1 \mathrm{mM}$ DTT, $0.1 \mathrm{mM}$ EDTA and $0.1 \%$ Triton $X-100$ ) and centrifuged at $12,000 \times g$ for $10 \mathrm{~min}$ at $4^{\circ} \mathrm{C}$. After determination of protein concentration BCA method (Pierce), the cell extract (50 $\mu \mathrm{g}$ of protein) was added to the assay buffer (100 mM HEPES, pH 7.4, 0.1\% CHAPS, $10 \mathrm{mM}$ DTT, $10 \%$ glycerol, and $2 \%(\mathrm{v} / \mathrm{v})$ dimethylsulfoxide) containing chromogenic substrates (2 $\mathrm{mM}$ ) and incubated for $4 \mathrm{~h}$ at $37^{\circ} \mathrm{C}$. Caspase activity was determined by measuring the absorbance at $405 \mathrm{~nm}$ according to the protocol (CaspACETM Assay System Kit; Promega).

\section{Western blot analysis}

Cells were lysed in buffer (50 mM Tris-Cl, pH 8.0, $150 \mathrm{mM}$ $\mathrm{NaCl}, 0.1 \%$ SDS, $1 \%$ Triton $\mathrm{X}-100,0.5 \%$ sodium deoxycholate and protease inhibitor cocktail) and centrifuged at $20,000 \times g$ for $30 \mathrm{~min}$ at $4^{\circ} \mathrm{C}$. After quantitating the protein concentration in each cell extract, the sample was subjected to SDS-PAGE and then transferred to nitrocellulose membrane. The membrane was blocked for $1 \mathrm{~h}$ with $5 \%$ skim milk in Tris-buffered saline, and incubated with the following antibodies: anti-TG2 (Jeon et al., 2003), anti-caspase-3 (Cell signaling), anti-PARP (Cell signaling), anti-caspase 9 (cell signaling), anti-Bcl-2 (SantaCruz), anti-Bcl- $X_{L}$ (Cell Signaling), anti-p-Bad (Cell signaling), anti-Bax (SantaCruz), anti-FAK (Signal transduction), anti-p-FAK (Signal transduction), anti-Akt (Cell signaling), anti-p-Akt (Cell signaling), anti-ERK (SantaCruz), anti-p-ERK (SantaCruz), anti-p38 (Cell signaling), anti-p-p38 (Cell signaling), anti-p-JNK (SantaCruz), and anti-Actin (Sigma) antibody. Each membrane was washed and incubated with horseradish peroxidase-conjugated secondary antibody, followed by enhanced chemiluminescence development according to the manufacture's instruction (Pierce).

\section{Cytochrome $c$ release from mitochondria}

Cytochrome $c$ released from mitochondria was assessed as previously described (Waterhouse et al., 2001). In brief, cells were centrifuged at $1,000 \times g$ for $5 \mathrm{~min}$ at $4^{\circ} \mathrm{C}$ and treated in PBS containing $80 \mathrm{mM} \mathrm{KCl}, 250 \mathrm{mM}$ sucrose, and $200 \mu \mathrm{g} / \mathrm{ml}$ digitonin (Sigma) for $5 \mathrm{~min}$ on ice. The cells were centrifuged at $10,000 \times \mathrm{g}$ for $5 \mathrm{~min}$ at $4^{\circ} \mathrm{C}$. The supernatant was used as cytosolic fraction. The pellet was lysed in buffer $(50 \mathrm{mM}$ Tris- $\mathrm{Cl}, \mathrm{pH} 7.5,150 \mathrm{mM} \mathrm{NaCl}, 2$ mM EDTA, 2 mM EGTA, $0.2 \%$ Triton $X-100$ and $0.3 \%$ NP-40) rocking for $10 \mathrm{~min}$ at $4^{\circ} \mathrm{C}$. The lysate was centrifuged at $10,000 \times g$ for $5 \mathrm{~min}$ at $4^{\circ} \mathrm{C}$. The supernatant was used as mitochondrial fraction. Cytosolic fraction $(30 \mu \mathrm{g})$ and mitochondrial fraction $(5 \mu \mathrm{g})$ were subjected to Western blot analysis, using anti-cytochrome $c$ antibody (Pharmingen). The protein level of Bax in each fraction was determined by Western blot analysis using anti-Bax antibody. Purity of fractions was estimated by Western blot analysis using anti- $\alpha$-tubulin (cytosolic marker; Sigma) and anti-ATP synthase F1 $\alpha$ (mitochondrial marker; MitoSciences) antibody.

\section{Assessment of mitochondria membrane depolarization}

Mitochondria membrane depolarization was evaluated using the lipophilic cationic probe JC-1 (Molecular Probes) according to the manufacturer's instruction. Cells were harvested, resuspended in PBS, and incubated with $2 \mu \mathrm{M}$ $\mathrm{JC}-1$ rotating slowly for $30 \mathrm{~min}$ at $37^{\circ} \mathrm{C}$. The cells were washed with PBS and analyzed by flow cytometry using $488 \mathrm{~nm}$ excitation coupled with either $530 / 30 \mathrm{~nm}$ or $585 / 42$ $\mathrm{nm}$ bypass emission filter. The cells without red fluorescence were considered as the cells manifesting mitochondria membrane depolarization.

\section{Real-time quantitative PCR}

RNA was purified with TRIzol reagent (Invitrogen). One microgram of purified RNA was reversely transcribed using Maxime RT premix kit (Takara) according to the manufacturers' instructions. Quantitative real-time PCR was performed using SYBR Green PCR Master Mix (Applied Biosystems). Hypoxanthine phosphoribosyltransferase 1 (HPRT1) was used as internal control for normalization. The sequences of primers for Bax were 5'-TCTACTTTGCCAGCAAACTGGTGC-3' and 5'-TGTCCAGCCCATGATGGTTCTGAT-3', and sequences for HPRT1 were 5'-TGACACTGGCAAAACAATGCA-3' and 5'-GGTCCTTTTCACCAGCAAGCT-3' (Jang et al., 2009). Conventional PCR was performed with same primers using Ex Taq polymerase (Takara).

\section{Statistical analysis}

All statistical calculations were performed using Prism 4.0 (GraphPad). Differences between two variables and multiple variables were assessed by unpaired Student's $t$ test and one-way ANOVA with Tukey's multiple comparison test, respectively. The difference was considered significant if the $P$ value was less than 0.05 .

\section{Acknowledgements}

We thank Dr. Y. D. Kim for critical comments on the manuscript, Dr. T. Gwan Park (Korea Advanced Institute of Science and Technology) for kindly providing the shRNA construct for GFP. This work was supported by the grants from Korea Science and Engineering Foundation (R012005-000-10364-0) and also by the Research Program for New Drug Target Discovery (M10748000296-07N480029610). S.Y.C., E.M.J., and G.Y.J. were supported by the graduate program of BK21, Korean Ministry of Education, Science and Technology. 


\section{References}

Acehan D, Jiang X, Morgan DG, Heuser JE, Wang X, Akey $\mathrm{CW}$. Three-dimensional structure of the apoptosome: implications for assembly, procaspase-9 binding, and activation. Mol Cell 2002;9:423-32

Akimov SS, Krylov D, Fleischman LF, Belkin AM. Tissue transglutaminase is an integrin-binding adhesion coreceptor for fibronectin. J Cell Biol 2000;148:825-38

Antonyak MA, Singh US, Lee DA, Boehm JE, Combs C, Zgola MM, Page RL, Cerione RA. Effects of tissue transglutaminase on retinoic acid-induced cellular differentiation and protection against apoptosis. J Biol Chem 2001;276:33582-7

Antonyak MA, McNeill CJ, Wakshlag JJ, Boehm JE, Cerione RA. Activation of the Ras-ERK pathway inhibits retinoic acid-induced stimulation of tissue transglutaminase expression in NIH3T3 cells. J Biol Chem 2003;278:15859-66

Antonyak MA, Miller AM, Jansen JM, Boehm JE, Balkman CE, Wakshlag JJ, Page RL, Cerione RA. Augmentation of tissue transglutaminase expression and activation by epidermal growth factor inhibit doxorubicin-induced apoptosis in human breast cancer cells. J Biol Chem 2004; 279:41461-7

Battaglia G, Farrace MG, Mastroberardino PG, Viti I, Fimia $\mathrm{GM}$, Van Beeumen J, et al. Transglutaminase 2 ablation leads to defective function of mitochondrial respiratory complex I affecting neuronal vulnerability in experimental models of extrapyramidal disorders. J Neurochem 2007; 100:36-49

Boehm JE, Singh U, Combs C, Antonyak MA, Cerione RA. Tissue transglutaminase protects against apoptosis by modifying the tumor suppressor protein p110 Rb. J Biol Chem 2002;277:20127-30

Brummelkamp TR, Bernards R, Agami R. A system for stable expression of short interfering RNAs in mammalian cells. Science 2002;296:550-3

Cory S, Huang DC, Adams JM. The Bcl-2 family: roles in cell survival and oncogenesis. Oncogene 2003;22:8590-607

De Laurenzi V, Melino G. Gene disruption of tissue transglutaminase. Mol Cell Biol 2001;21:148-55

Dong Z, Saikumar P, Weinberg JM, Venkatachalam MA. Calcium in cell injury and death. Annu Rev Pathol 2006;1: 405-34

Fesus L, Thomazy V, Falus A. Induction and activation of tissue transglutaminase during programmed cell death. FEBS Lett 1987;224:104-8

Fesus L, Davies PJ, Piacentini M. Apoptosis: molecular mechanisms in programmed cell death. Eur $\mathrm{J}$ Cell Biol 1991;56:170-7

Fesus L, Szondy Z. Transglutaminase 2 in the balance of cell death and survival. FEBS Lett 2005;579:3297-302

Green DR. Apoptotic pathways: the roads to ruin. Cell 1998;94:695-8

Gu JJ, Gathy K, Santiago L, Chen E, Huang M, Graves LM,
Mitchell BS. Induction of apoptosis in IL-3-dependent hematopoietic cell lines by guanine nucleotide depletion. Blood 2003;101:4958-65

Gundemir S, Johnson GV. Intracellular localization and conformational state of transglutaminase 2: implications for cell death. PLoS One 2009;4:e6123

Honda HM, Korge P, Weiss JN. Mitochondria and ischemia/reperfusion injury. Ann N Y Acad Sci 2005; 1047: 248-58

Humar M, Graetz C, Roesslein M, Goebel U, Geiger KK, Heimrich B, Pannen BH. Heterocyclic thioureylenes protect from calcium-dependent neuronal cell death. Mol Pharmacol 2009;75:667-76

Hwa Kim S, Hoon Jeong J, Chul Cho K, Wan Kim S, Gwan Park T. Target-specific gene silencing by siRNA plasmid DNA complexed with folate-modified poly(ethylenimine). J Control Release 2005;104:223-32

Jang GY, Jeon JH, Cho SY, Shin DM, Kim CW, Jeong EM, Bae HC, Kim TW, Lee SH, Choi Y, Lee DS, Park SC, Kim IG. Transglutaminase 2 suppresses apoptosis by modulating caspase 3 and NF-kappaB activity in hypoxic tumor cells. Oncogene 2010;29:356-67

Jang $\mathrm{H}$, Choi SY, Cho EJ, Youn HD. Cabin1 restrains p53 activity on chromatin. Nat Struct Mol Biol 2009;16:910-5

Jeon JH, Kim CW, Shin DM, Kim K, Cho SY, Kwon JC, Choi $\mathrm{KH}$, Kang HS, Kim IG. Differential incorporation of biotinylated polyamines by transglutaminase 2 . FEBS Lett 2003;534:180-4

Kweon SM, Lee ZW, Yi SJ, Kim YM, Han JA, Paik SG, Ha SS. Protective role of tissue transglutaminase in the cell death induced by TNF-alpha in SH-SY5Y neuroblastoma cells. $J$ Biochem Mol Biol 2004;37:185-91

Lee SK, Kim YS, Lee SS, Lee YJ, Song IS, Park SC, Chi JG, Chung SI. Antisense inhibition of transglutaminase 2 affects development of mouse embryo submandibular gland in organ culture. Arch Oral Biol 2005;50:789-98

Lorand L, Graham RM. Transglutaminases: crosslinking enzymes with pleiotropic functions. Nat Rev Mol Cell Biol 2003;4:140-56

Malorni W, Farrace MG, Matarrese P, Tinari A, Ciarlo L, Mousavi-Shafaei $P$, et al. The adenine nucleotide translocator 1 acts as a type 2 transglutaminase substrate: implications for mitochondrial-dependent apoptosis. Cell Death Differ 2009; 16:1480-92

Mastroberardino PG, Farrace MG, Viti I, Pavone F, Fimia GM, Melino G, Rodolfo C, Piacentini M. "Tissue" transglutaminase contributes to the formation of disulphide bridges in proteins of mitochondrial respiratory complexes. Biochim Biophys Acta 2006;1757:1357-65

Milakovic T, Tucholski J, McCoy E, Johnson GV. Intracellular localization and activity state of tissue transglutaminase differentially impacts cell death. J Biol Chem 2004;279: 8715-22

Nakaoka H, Perez DM, Baek KJ, Das T, Husain A, Misono K, Im MJ, Graham RM. Gh: a GTP-binding protein with transglutaminase activity and receptor signaling function. 


\section{Science 1994;264:1593-6}

Nanda N, lismaa SE, Owens WA, Husain A, Mackay F, Graham RM. Targeted inactivation of Gh/tissue transglutaminase II. J Biol Chem 2001;276:20673-8

Oliverio S, Amendola A, Rodolfo C, Spinedi A, Piacentini M. Inhibition of "tissue" transglutaminase increases cell survival by preventing apoptosis. J Biol Chem 1999;274:34123-8

Orrenius S, Zhivotovsky B, Nicotera P. Regulation of cell death: the calcium-apoptosis link. Nat Rev Mol Cell Biol 2003;4:552-65

Park KS, Han BG, Lee KH, Kim DS, Kim JM, Jeon H, et al. Depletion of nucleophosmin via transglutaminase 2 crosslinking increases drug resistance in cancer cells. Cancer Lett 2008;274:201-7

Parsons JT. Focal adhesion kinase: the first ten years. J Cell Sci 2003;116:1409-16

Piacentini M, Farrace MG, Piredda L, Matarrese P, Ciccosanti F, Falasca $\mathrm{L}$, et al. Transglutaminase overexpression sensitizes neuronal cell lines to apoptosis by increasing mitochondrial membrane potential and cellular oxidative stress. J Neurochem 2002;81:1061-72

Reddy KB, Nabha SM, Atanaskova N. Role of MAP kinase in tumor progression and invasion. Cancer Metastasis Rev 2003;22:395-403

Robitaille K, Daviau A, Lachance G, Couture JP, Blouin R. Calphostin $\mathrm{C}$-induced apoptosis is mediated by a tissue transglutaminase-dependent mechanism involving the DLK/JNK signaling pathway. Cell Death Differ 2008;15: 1522-31

Rodolfo C, Mormone E, Matarrese P, Ciccosanti F, Farrace MG, Garofano E, Piredda L, Fimia GM, Malorni W, Piacentini $\mathrm{M}$. Tissue transglutaminase is a multifunctional $\mathrm{BH}$-only protein. J Biol Chem 2004;279:54783-92

Shin DM, Jeon JH, Kim CW, Cho SY, Lee HJ, Jang GY, et al. TGFbeta mediates activation of transglutaminase 2 in response to oxidative stress that leads to protein aggregation. FASEB J 2008;22:2498-507

Singh US, Pan J, Kao YL, Joshi S, Young KL, Baker KM. Tissue transglutaminase mediates activation of RhoA and MAP kinase pathways during retinoic acid-induced neuronal differentiation of SH-SY5Y cells. J Biol Chem 2003;278: 391-9

Slaughter TF, Achyuthan KE, Lai TS, Greenberg CS. A microtiter plate transglutaminase assay utilizing 5-(biotinamido)pentylamine as substrate. Anal Biochem 1992;205: 166-71

Szondy Z, Mastroberardino PG, Váradi J, Farrace MG, Nagy $\mathrm{N}$, Bak I, et al. Tissue transglutaminase (TG2) protects cardiomyocytes against ischemia/reperfusion injury by regulating ATP synthesis. Cell Death Differ 2006;13:1827-9

Tatsukawa H, Fukaya Y, Frampton G, Martinez-Fuentes A, Suzuki K, Kuo TF, Nagatsuma K, Shimokado K, Okuno M, Wu J, lismaa S, Matsuura T, Tsukamoto H, Zern MA, Graham RM, Kojima S. Role of transglutaminase 2 in liver injury via cross-linking and silencing of transcription factor Sp1. Gastroenterology 2009;136:1783-95

Tucholski J, Johnson GV. Tissue transglutaminase differentially modulates apoptosis in a stimuli-dependent manner. $J$ Neurochem 2002;81:780-91

Tucholski J. TG2 protects neuroblastoma cells against DNA-damage-induced stress, suppresses p53 activation. Amino Acids 2010;39:523-32

Waterhouse NJ, Goldstein JC, Kluck RM, Newmeyer DD, Green DR. The (Holey) study of mitochondria in apoptosis. Methods Cell Biol 2001;66:365-91

Wei MC, Zong WX, Cheng EH, Lindsten T, Panoutsakopoulou V, Ross AJ, Roth KA, MacGregor GR, Thompson CB, Korsmeyer SJ. Proapoptotic BAX and BAK: a requisite gateway to mitochondrial dysfunction and death Science 2001;292:727-30 